\title{
16S rRNA PCR-Denaturing Gradient Gel Electrophoresis of Oral Lactobacillus casei Group and Their Phenotypic Appearances
}

\author{
S. Piwat ${ }^{1,2}$ and R. Teanpaisan ${ }^{1,3}$ \\ ${ }^{1}$ Common Oral Diseases and Epidemiology Research Center, Faculty of Dentistry, Prince of Songkla University, Hat Yai 90112, Thailand \\ ${ }^{2}$ Department of Preventive Dentistry, Faculty of Dentistry, Prince of Songkla University, Hat Yai 90112, Thailand \\ ${ }^{3}$ Department of Stomatology, Faculty of Dentistry, Prince of Songkla University, Hat Yai 90112, Thailand
}

Correspondence should be addressed to R. Teanpaisan; rawee.t@psu.ac.th

Received 29 June 2013; Accepted 25 August 2013

Academic Editors: O. Pepe and A. Sunna

Copyright (C) 2013 S. Piwat and R. Teanpaisan. This is an open access article distributed under the Creative Commons Attribution License, which permits unrestricted use, distribution, and reproduction in any medium, provided the original work is properly cited.

\begin{abstract}
This study aimed to develop a $16 \mathrm{~S}$ rRNA PCR-denaturing gradient gel electrophoresis (DGGE) to identify the species level of Lactobacillus casei group and to investigate their characteristics of acid production and inhibitory effect. PCR-DGGE has been developed based on the 16S rRNA gene, and a set of HDA-1-GC and HDA-2, designed at V2-V3 region, and another set of CARP1-GC and CARP-2, designed at V1 region, have been used. The bacterial strains included L. casei ATCC 393, L. paracasei CCUG 32212, L. rhamnosus ATCC 7469, L. zeae CCUG 35515, and 46 clinical strains of L. casei/paracasei/rhamnosus. Inhibitory effect against Streptococcus mutans and acid production were examined. Results revealed that each type species strain and identified clinical isolate showed its own unique DGGE pattern using CARP1-GC and CARP2 primers. HDA1-GC and HDA2 primers could distinguish the strains of $L$. paracasei from $L$. casei. It was found that inhibitory effect of $L$. paracase $i$ was stronger than $L$. case $i$ and L. rhamnosus. The acid production of L. paracasei was lower than L. casei and L. rhamnosus. In conclusion, the technique has been proven to be able to differentiate between closely related species in $L$. casei group and thus provide reliable information of their phenotypic appearances.
\end{abstract}

\section{Introduction}

Lactobacillus strains are extensively used as probiotics in the food industry, and certain Lactobacillus species are also of importance in general health, providing a beneficial microflora in the oral cavity [1], intestinal tract $[2,3]$, and vagina [4]. The genus Lactobacillus contains a diverse assemble of Gram-positive, catalase negative, and nonsporulating, rod-shaped organisms and includes more than 140 species $[5,6]$. Among those, Lactobacillus casei group, especially L. casei, L. paracasei, and L. rhamnosus, has attracted a lot of attention over the last 20 years. This is linked to the considerable economic importance of the L. (para)casei species, which is used in many food and feed applications such as dairy products and has a proven record in human and animal health. However, the taxonomy among the species in Lactobacillus casei group is still vague. The uncertain identification leads to confusion in phenotypic characters.
In recent years, the identification of lactobacilli evolving along with molecular methods based upon the 16S rRNA gene has been widely used. However, it is still difficult to differentiate unambiguously among these species. Many attempts to discriminate these species yielded inaccurate results, and only limited success could be achieved, largely due to the failure of differentiation between $L$. paracasei and $L$. casei strains [7-10]. For example, most of the strains described as $L$. casei much more differ from the species type strain of ATCC $393^{T}$ than from L. zeae strains $[11,12]$. In addition, L. paracasei strains and L. casei ATCC 334 are indistinguishable [13]. Thus, reliable and practical techniques to identify such strains are required. The technique of PCRdenaturing gradient gel electrophoresis (DGGE) has been introduced recently. This technique provides the information of variations in target genes within bacterial population which allows differentiating among the species that the DNA sequences differs in at least one base pair. In this study, it 
revealed that the DGGE method with the designed primers of the V1 and region of V2-V3 region of $16 \mathrm{~S}$ rRNA genes enabled to distinguish among the species of $L$. casei, L. paracasei, L. rhamnosus, and L. zeae. In addition, the phenotypic characters of acid production and inhibitory effect on oral pathogen were analyzed.

\section{Materials and Methods}

2.1. Bacterial and Culture Conditions. Four reference strains of Lactobacillus casei ATCC $393^{\mathrm{T}}$, L. paracasei CCUG 32212, Lactobacillus rhamnosus ATCC $7469^{\mathrm{T}}$, and L. zeae CCUG $35515^{\mathrm{T}}$ and 46 clinical strains, $10 \mathrm{~L}$. case i isolates, $21 \mathrm{~L}$. paracasei isolates and $15 \mathrm{~L}$. rhamnosus isolates, were included in this study. All clinical strains were previously identified according to 16S-rRNA gene profiles by restriction fragment length polymorphism analysis (PCR-RFLP) and protein profiles by sodium dodecyl sulfate polyacrylamide gel electrophoresis (SDS-PAGE) [14]. The identification was also confirmed using sequencing of $16 \mathrm{~S}$ rRNA genes.

2.2. Primers Used. Two set of primers were used in this study, the first set of primers was HDA-1-GC ( $5^{\prime}$ CGCCCGGGGCGCGCCCCGGGCGGGGCGGGGGCA CGGGGGGACTCCTACGGGAGGCAGCAGT-3' ${ }^{\prime}$ and HDA-2 (5'-GTATTACCGCGGCTGCTGGCAC- $\left.{ }^{\prime}\right)$ according to Walter et al. [10], which was designed targeting $200 \mathrm{bp}$ of the V2-V3 region of 16S-rRNA gene. The second set of primers was CARP-1-GC $\left(5^{\prime}-\right.$ CGCCCGGGGCGCGCCCCGGGCGGGGCGGGGGCA CGGGGGGGGCGTGCCTAATACATGCAA- $3^{\prime}$ ) and CARP-2 ( $5^{\prime}$-GGCAGGTTACCCACGTGTT- $\left.3^{\prime}\right)$, which was designed in this study targeting $112 \mathrm{bp}$ of the $\mathrm{V} 1$ region.

2.3. PCR-DGGE. All DNA samples were extracted using a Genomic DNA Extraction Kit (RBC Bioscience, Taipei, Taiwan), following the manufacturer's protocol for Grampositive bacteria. The condition of PCR was that each $50 \mu \mathrm{L}$ PCR reaction contained $10 \mathrm{mM}$ Tris- $\mathrm{HCl}$ pH 8.3, $50 \mathrm{mM} \mathrm{KCl}$ (GeneAmp PCR buffer II from Applied Biosystems, Foster City, CA, USA), $1 \mathrm{mM} \mathrm{MgCl} 2$ (Applied Biosystems), $0.1 \mathrm{mM}$ each dNTP, $0.4 \mu \mathrm{M}$ both primers, $5 \mu \mathrm{g} / \mathrm{mL}$ template, and 0.5 U Ampli-Taq DNA polymerase (Applied Biosystems). The PCR reactions were run using a GeneAmp PCR System 2400 (Applied Biosystems, Foster, CA, USA). For primers CARP-1-GC and CARP-2, reactions were run with an initial touchdown step in which the annealing temperature was lowered from 61 to $57^{\circ} \mathrm{C}$ in intervals of $2^{\circ} \mathrm{C}$ every 3 cycles, and 20 additional cycles were done with annealing at $55^{\circ} \mathrm{C}$. Denaturation was performed at $95^{\circ} \mathrm{C}$ for $1 \mathrm{~min}$, and extension was performed at $72^{\circ} \mathrm{C}$ for $1 \mathrm{~min}$ and $30 \mathrm{~s}$. For primers HDA-1-GC and HDA-2, reactions were run for 35 cycles of denaturation at $95^{\circ} \mathrm{C}$ for $60 \mathrm{~s}$, annealing at $56^{\circ} \mathrm{C}$ for $45 \mathrm{~s}$, and extension at $72^{\circ} \mathrm{C}$ for $60 \mathrm{~s}$. For both amplification cycles, an initial denaturation at $94^{\circ} \mathrm{C}$ for $5 \mathrm{~min}$ and a final extension at $72^{\circ} \mathrm{C}$ for $7 \mathrm{~min}$ were carried out.
2.4. DGGE Analysis. The Dcode Universal Mutation Detection System (BioRad, Hercules, CA, USA) was used for the sequence-specific separation of the PCR products. Electrophoresis was performed in a $8 \%$ polyacrylamide gel with gradient of 35 to $60 \%$ urea-formamide denaturant, and electrophoresis running time was adjusted to $6 \mathrm{~h}$ at $120 \mathrm{~V}$. After electrophoresis, they were stained for $10 \mathrm{~min}$ in a SYBR Green solution (Molecular Probes, OR, USA) and analyzed under UV illumination.

2.5. Inhibitory Effect of Lactobacillus against Streptococcus mutans ATCC 25175. The inhibitory effect of the Lactobacillus strains against Streptococcus mutans ATCC 25175 was assessed by an agar overlay method [15]. In brief, Lactobacillus strains (producer strains) were inoculated on the surface of the brain heart infusion agar and incubated anaerobically $\left(80 \% \mathrm{~N}_{2}, 10 \% \mathrm{H}_{2}\right.$, and $\left.10 \% \mathrm{CO}_{2}\right)$ for $24-48 \mathrm{~h}$ at $37^{\circ} \mathrm{C}$ to develop visible macrocolonies. S. mutans ATCC 25175 was used as an indicator strain. The indicator strain was precultivated in the brain heart infusion broth (BHI), and the suspension of cells was adjusted to an optical density (OD) 0.25 at $600 \mathrm{~nm}$. Thereafter, $5 \mathrm{~mL}$ of BHI soft agar (7 g/L agar) was seeded with $100 \mathrm{uL}$ of an overnight culture of the indicator strain and immediately poured over the macrocolonies of Lactobacillus. The plates were incubated anaerobically at $37^{\circ} \mathrm{C}$ for $24 \mathrm{~h}$ to generate an inhibitory zone. The experiments were performed in triplicate.

2.6. Measurement of Acid Production. The acid production of the Lactobacillus strains was assessed according to Piwat et al. [16]. Lactobacillus strains were initially grown anaerobically $\left(80 \% \mathrm{~N}_{2}, 10 \% \mathrm{H}_{2}\right.$, and $10 \% \mathrm{CO}_{2}$ ) to exponential phase in filter sterilized (pore size $0.22 \mu \mathrm{m}$, Nalgene, NY, USA) de Man, Rogosa and Sharpe (MRS) broth (Lab M, Bury, UK) at $37^{\circ} \mathrm{C}$ for $16-18 \mathrm{~h}$. Cells were harvested by centrifugation at $3000 \mathrm{rpm}$ for $5 \mathrm{~min}$ at $4^{\circ} \mathrm{C}$, washed twice in phosphate buffered saline (PBS; Oxoid, Basingstoke, UK), and inoculated into $50 \mathrm{~mL}$ fresh, prewarmed MRS broth containing $2 \%(\mathrm{w} / \mathrm{v})$ glucose, $\mathrm{pH} 7.0$, to give an optical density of 1.0 at $650 \mathrm{~nm}$ (corresponding to $10^{10}$ cells $/ \mathrm{mL}$ ). The cultures were then incubated in an anaerobic chamber (miniMacs Anaerobic Workstation, Don Whitley Scientific Ltd, UK) at $37^{\circ} \mathrm{C}$.

Two milliliters of each sample was collected and analyzed for the growth and acid production at the start (0) and after $1.5,3,5,7$, and $24 \mathrm{~h}$. Bacterial growth was determined by measuring the final OD reached at $650 \mathrm{~nm}$, and the change in OD was calculated. In addition, the number of viable cells was also counted as $\mathrm{CFU} / \mathrm{mL}$ on MRS agar following anaerobic incubation for $48 \mathrm{~h}$.

Acid production was studied by $\mathrm{pH}$ measurements using a pH electrode and $\mathrm{pH}-$ meter (Hanna $\mathrm{pH}$ 211, Hanna Instrument, UK). The amount of hydrogen ion $\left[\mathrm{H}^{+}\right]$was obtained from $\mathrm{pH}$ values according to the formula: $\left[\mathrm{H}^{+}\right]=\left(10^{\mathrm{pH}}\right)^{-1}$.

The rate of acidification by each strain (acid production rate) was determined from the change in $\mathrm{H}^{+}\left(\delta \mathrm{H}^{+}\right)$divided 
by the average number of bacterial cells per hour in the logarithmic growth phase, as shown in the following equation:

$$
\text { acid production rate }=\frac{\left(\delta \mathrm{H}^{+}\right)}{\left[\left(\left(N_{2}-N_{1}\right) / 2\right) * t_{2}-t_{1}\right]},
$$

where $N_{1}$ and $N_{2}$ are number of bacterial cells at time point 1 $\left(t_{1}\right)$ and time point $2\left(t_{2}\right)$, respectively. The data presented are means of triplicate measurements, and all experiments were performed twice.

\section{Results}

The DGGE patterns of V1 region of 16S rRNA sequences are shown in Figure 1, and each type species strain and identified clinical isolate showed its own unique DGGE pattern. L. rhamnosus ATCC 7469 and identified clinical isolates revealed a different band from L. zeae CCUG 35515, L. casei ATCC 393, and L. paracasei CCUG 32212. It was noted that those of clinical strains identified as $L$. casei gave the different DGGE patterns from the type strain L. casei ATCC 393. All clinical strains identified as $L$. casei had a major band with the same distance as $L$. paracasei strains; however, L. paracasei CCUG 32212 and most of clinical isolates identified $L$. paracasei showed the extraminor bands. When HDA1 and HDA2 primers were used to produce the DGGE patterns of V2-V3 region of $16 \mathrm{~S}$ rRNA sequences, $L$. casei ATCC 393 showed the same DGGE pattern as all clinical strains identified as L. casei. L. paracasei CCUG 32212 and all clinical isolates revealed the same multiple bands which clearly differed from all L. casei strains (Figure 2).

The ability for growth inhibition of $L$. casei group against S. mutans ATCC 25175 is shown in Figure 3. A statistically significant difference among the species was found (KruskalWallis Test, $P<0.05$ ) after $L$. paracasei strains were identified separately. $L$. paracasei strains had a significantly higher inhibitory effect than either L. casei or L. rhamnosus (MannWhitney $U$ Test, $P<0.01$ ).

Acid-production rate of clinical strains of $L$. casei group in the exponential growth phase was calculated from the 1.5 to $5 \mathrm{~h}$ incubation period. Also, a statistically significant difference among the species was found (Kruskal-Wallis Test, $P<0.05)$ after $L$. paracasei strains were identified separately. $L$. paracasei strains had a significantly lower acid-production rate than either L. casei or L. rhamnosus (Mann-Whitney $U$ Test, $P<0.05$ ) (Figure 4).

\section{Discussion}

The Lactobacillus casei group is one of special relevance for dairy food (cheese, yoghurt, and other fermented milk products) and pharmaceutical industry due to its important role in promoting human health. Based on their ability to inhibit the growth of various pathogens, they have been used as probiotics in the gut for decades [17]. Previously, a single species with five subspecies has been reclassified into three species including $L$. casei, $L$. paracasei, and $L$. rhamnosus in 1989 [18]. However, this classification initiated a controversy, generally due to the failure of differentiation

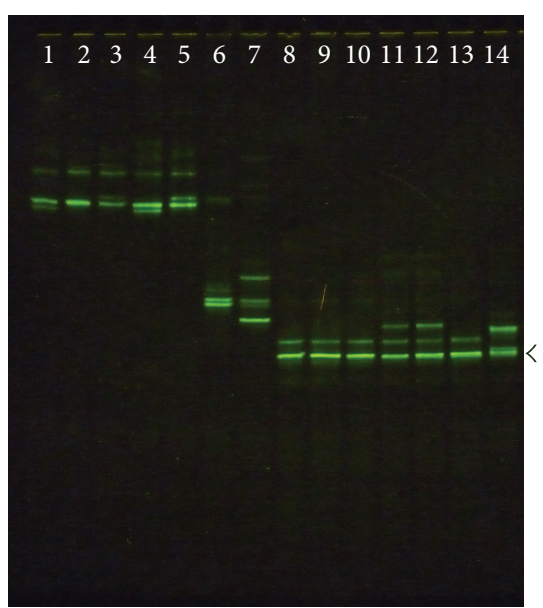

FIGURE 1: The DGGE patterns, V1 region of $16 \mathrm{~S}$ rRNA, of Lactobacillus casei group in the 35-60\% denaturant gel. Lane 1, L. rhamnosus ATCC 7469; Lanes 2-5, L. rhamnosus clinical isolates; Lane 6, L. zeae CCUG 35515; Lane 7, L. casei ATCC 393; Lanes 8-10, L. casei clinical isolates; Lane 11, L. paracasei CCUG 32212; Lanes 12-14, L. paracasei clinical isolates. The arrow indicates the major fragment of $L$. case $i$ and $L$. paracasei strains.

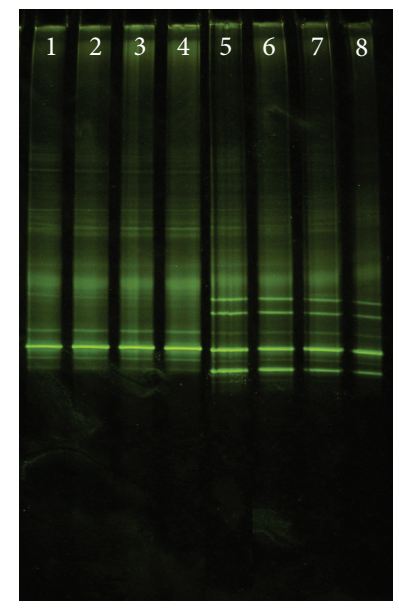

FIgURE 2: The DGGE patterns, V2-V3 region of $16 \mathrm{~S}$ rRNA, of Lactobacillus casei group in the 35-60\% denaturant gel. Lane 1, L. casei ATCC 393; Lanes 2-4, L. casei clinical isolates; Lane 5, L. paracasei CCUG 32212; Lanes 6-8, L. paracasei clinical isolates.

between $L$. paracasei and former $L$. casei strains even by molecular technique [19-21] including our previous study [14].

Research has been focused on the application of molecular biology techniques for accurate differentiation among the strains. We developed a DGGE method with the designed primers of the V1 in combination with V2-V3 region of $16 \mathrm{~S}$ rRNA genes, which enabled to distinguish the close related strains in the $L$. casei group. It was shown that CARP1GC and CARP2 primers could clearly distinguish the type strain L. rhamnosus ATCC 7469, L. zeae CCUG 35515, L. casei ATCC 393, and L. paracasei CCUG 32212 from each other, and each individual revealed its own unique pattern 


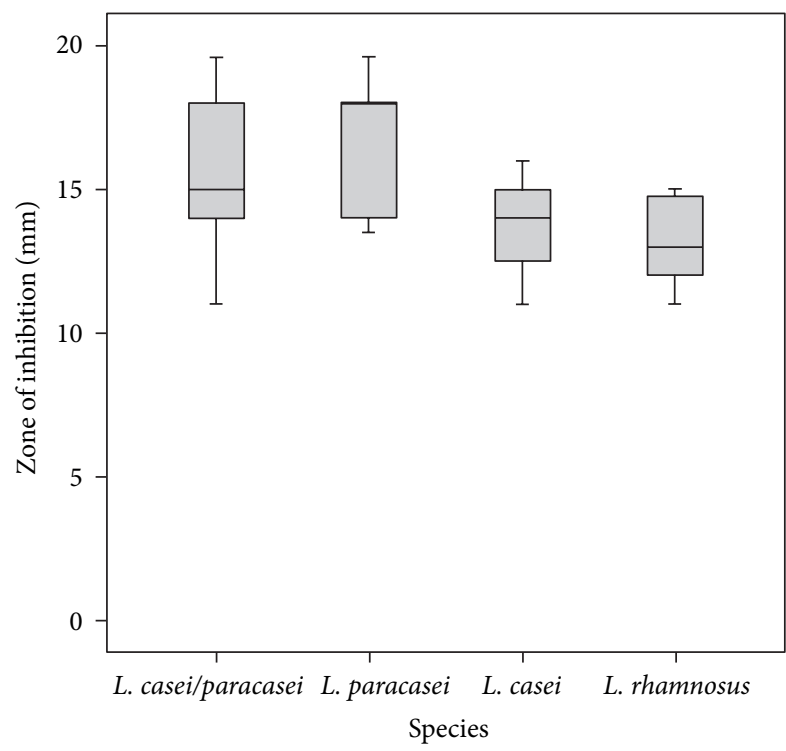

Figure 3: Inhibitory effects of clinical strains of $L$. casei/paracasei/rhamnosus against S. mutans ATCC 25175. Boxplot shows median, percentile (first and third percentile), and the minimum-maximum distribution of value.

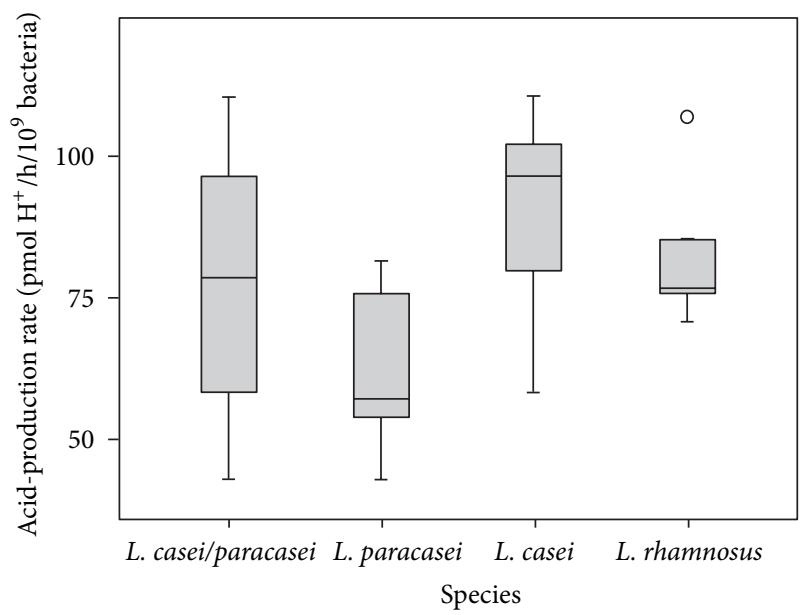

Figure 4: Acid-production rate of clinical strains of $L$. casei/paracasei/rhamnosus in the exponential growth phase. Results were calculated from the 1.5 to $5 \mathrm{~h}$ incubation period. Boxplots show median, percentile (first and third percentile), and the maximum-minimum values. Outlier values are presented as dots.

(Figure 1). It was surprising that those of clinical strains identified as $L$. casei gave different DGGE patterns from the type strain L. casei ATCC 393. The results indicated that there were different sequences in V1 region of all the type strains, which confirmed the information obtained by comparing the published 16S rRNA gene sequences of the type strain $L$. rhamnosus ATCC 7469, L. zeae CCUG 35515, L. casei ATCC 393, and L. paracasei CCUG 32212 [22].

HDA1-GC and HDA2 primers could distinguish the type strain and identified clinical isolates of $L$. casei from the type strain and identified clinical isolates of $L$. paracasei (Figure 2). By showing the multiple bands of all strains of $L$. paracasei, it indicated that $L$. paracasei strains contained more than one copy of $16 \mathrm{~S}$ rRNA gene. This has been confirmed by DNA sequencing (data not shown). It is likely that the taxonomy of this group will undergo further changes with more extensive studies providing more evidence in the coming years. Thus, such method may assist in future taxonomic considerations of this group and could be a beneficial implementation for future research.

In oral cavity, lactobacilli have frequently been isolated from carious lesions, and thus, they are thought to be associated with the development of dental caries. The reason was based on their acid production and aciduric characteristics $[16,23,24]$. As many Lactobacillus species have similar nutritional and growth requirements, it is often difficult to use classical microbiological methods to identify close related species. Consequently, in most of the dental literature, they are specified and are referred to only as lactobacilli. However, it is important to understand the certain role of various lactobacilli, whether they are harmful, beneficial, or neutral for the development of dental caries.

Nowadays, Lactobacillus was increasingly used as probiotic bacteria in the oral cavity [1]. The inhibitory activities of oral Lactobacillus against oral pathogens, for example, cariogenic bacteria, periodontopathogens, and Candida, have been reported $[15,25,26]$. However, the cariogenic characteristics of Lactobacillus, especially acidogenic activity, have always been concerned [27]. In most clinical studies, L. casei and $L$. paracase $i$ have always been grouped together due to difficulties in their differentiation. They have been reported for their association with dental caries in several studies [28 -30]. However, less is known of how acidogenicity and inhibitory activity differ among these two species identified with current taxonomic methods. In this study, the heterogeneity of acid production and antimicrobial effect among the species of $L$. casei/L. paracasei/L. rhamnosus were clear when their identification was performed properly. It was found that $L$. paracasei strains were stronger in growth inhibition against oral pathogens and were weaker in acid production. The results indicated that $L$. paracasei may be of benefit as probiotics for the prevention of oral diseases than the others due to its low acidogenic and high inhibition effect.

In conclusion, the technique has been proven to be able to differentiate between closely related species in $L$. casei group and thus provide reliable information of their phenotypic appearances.

\section{Conflict of Interests}

The authors declare that they do not have a direct financial relation with the commercial identity mentioned in this paper that might lead to a conflict of interests for any of the authors.

\section{Acknowledgments}

This study was supported by the Higher Education Research Promotion and National Research University project of 
Thailand Office of the Higher Education Commission (AGR $540555 \mathrm{M})$, the National Science and Technology Development Agency (NSTDA) of Thailand, and the National Research Council of Thailand. The authors are very grateful to Professor Gunnar Dahlen, Department of Oral Microbiology, Institute of Odontology, Sahlgrenska Academy at Gothenburg University, Gothenburg, Sweden, for providing the type strains used.

\section{References}

[1] J. H. Meurman and I. Stamatova, "Probiotics: contributions to oral health," Oral Diseases, vol. 13, no. 5, pp. 443-451, 2007.

[2] S. Salminen, A. C. Ouwehand, and E. Isolauri, "Clinical applications of probiotic bacteria," International Dairy Journal, vol. 8, no. 5-6, pp. 563-572, 1998.

[3] S. Parvez, K. A. Malik, S. Ah Kang, and H.-Y. Kim, "Probiotics and their fermented food products are beneficial for health," Journal of Applied Microbiology, vol. 100, no. 6, pp. 1171-1185, 2006.

[4] R. Hemalatha, P. Mastromarino, B. A. Ramalaxmi, N. V. Balakrishna, and B. Sesikeran, "Effectiveness of vaginal tablets containing lactobacilli versus $\mathrm{pH}$ tablets on vaginal health and inflammatory cytokines: a randomized, double-blind study," European Journal of Clinical Microbiology and Infectious Diseases, vol. 31, no. 11, pp. 3097-3105, 2012.

[5] M. D. Collins, U. Rodrigues, C. Ash et al., "Phylogenetic analysis of the genus Lactobacillus and related lactic acid bacteria as determined by reverse transcriptase sequencing of $16 \mathrm{~S}$ rRNA," FEMS Microbiology Letters, vol. 77, no. 1, pp. 5-12, 1991.

[6] G. E. Felis and F. Dellaglio, "Taxonomy of lactobacilli and bifidobacteria," Current Issues in Intestinal Microbiology, vol. 8, no. 2, pp. 44-61, 2007.

[7] F. Chavagnat, M. Haueter, J. Jimeno, and M. G. Casey, "Comparison of partial tuf gene sequences for the identification of lactobacilli," FEMS Microbiology Letters, vol. 217, no. 2, pp. 177183,2002

[8] C. M. Dobson, B. Chaban, H. Deneer, and B. Ziola, "Lactobacillus casei, Lactobacillus rhamnosus, and Lactobacillus zeae isolates identified by sequence signature and immunoblot phenotype," Canadian Journal of Microbiology, vol. 50, no. 7, pp. 482-488, 2004.

[9] A. Vásquez, S. Ahrné, B. Pettersson, and G. Molin, “Temporal temperature gradient gel electrophoresis (TTGE) as a tool for identification of Lactobacillus casei, Lactobacillus paracasei, Lactobacillus zeae and Lactobacillus rhamnosus," Letters in Applied Microbiology, vol. 32, no. 4, pp. 215-219, 2001.

[10] J. Walter, G. W. Tannock, A. Tilsala-Timisjarvi et al., "Detection and identification of gastrointestinal Lactobacillus species by using denaturing gradient gel electrophoresis and speciesspecific PCR primers," Applied and Environmental Microbiology, vol. 66 , no. 1, pp. 297-303, 2000.

[11] B. Biavati, "International Committee of Systematic Bacteriology. Subcommitee on the taxonomy of Bifidobacterium, Lactobacillus and related organisms. Minutes of meeting, 22 and 23 August 1996," International Journal of Systematic and Evolutionary Microbiology, vol. 51, no. 6, pp. 257-258, 2001.

[12] G. Klein, "International Committee of Systematic Bacteriology. Subcommitee on the taxonomy of Bifidobacterium, Lactobacillus and related organisms. Minutes of meeting, 22 and 23 September 1999," International Journal of Systematic and Evolutionary Microbiology, vol. 51, no. 6, pp. 259-261, 2001.
[13] G. E. Felis, F. Dellaglio, L. Mizzi, and S. Torriani, "Comparative sequence analysis of a $r e c A$ gene fragment brings new evidence for a change in the taxonomy of the Lactobacillus casei group," International Journal of Systematic and Evolutionary Microbiology, vol. 51, no. 6, pp. 2113-2117, 2001.

[14] R. Teanpaisan and G. Dahlén, "Use of polymerase chain reaction techniques and sodium dodecyl sulfate-polyacrylamide gel electrophoresis for differentiation of oral Lactobacillus species," Oral Microbiology and Immunology, vol. 21, no. 2, pp. 79-83, 2006.

[15] R. Teanpaisan, S. Piwat, and G. Dahlén, "Inhibitory effect of oral Lactobacillus against oral pathogens," Letters in Applied Microbiology, vol. 53, no. 4, pp. 452-459, 2011.

[16] S. Piwat, R. Teanpaisan, G. Dahlén, S. Thitasomakul, and C. W. Douglas, "Acid production and growth by oral Lactobacillus species in vitro," Journal of Investigative and Clinical Dentistry, vol. 3, no. 1, pp. 56-61, 2012.

[17] S. Santosa, E. Farnworth, and P. J. H. Jones, "Probiotics and their potential health claims," Nutrition Reviews, vol. 64, no. 6, pp. 265-274, 2006.

[18] M. D. Collins, B. A. Phillips, and P. Zanoni, "Deoxyribonucleic acid homology studies of Lactobacillus casei, Lactobacillus paracasei sp. nov., subsp. paracasei and subsp. tolerans, and Lactobacillus rhamnosus sp. nov., comb. nov," International Journal of Systematic Bacteriology, vol. 39, no. 2, pp. 105-108, 1989.

[19] H. Chen, C. K. Lim, Y. K. Lee, and Y. N. Chan, "Comparative analysis of the genes encoding 23S-5S rRNA intergenic spacer regions of Lactobacillus casei-related strains," International Journal of Systematic and Evolutionary Microbiology, vol. 50, no. 2, pp. 471-478, 2000.

[20] F. Dellaglio, L. M. T. Dicks, M. Du Toit, and S. Torriani, "Designation of ATCC 334 in place of ATCC 393 (NCDO 161) as the neotype strain of Lactobacillus casei subsp. casei and rejection of the name Lactobacillus paracasei," International Journal of Systematic Bacteriology, vol. 41, no. 2, pp. 340-342, 1991.

[21] F. Dellaglio, G. E. Felis, and S. Torriani, "The status of the species Lactobacillus casei (Orla-Jensen 1916) Hansen and lessel 1971 and Lactobacillus paracasei Collins et al. 1989. Request for an opinion," International Journal of Systematic and Evolutionary Microbiology, vol. 52, no. 1, pp. 285-287, 2002.

[22] A. Vásquez, G. Molin, B. Pettersson, M. Antonsson, and S. Ahrné, "DNA-based classification and sequence heterogeneities in the 16S rRNA genes of Lactobacillus casei/paracasei and related species," Systematic and Applied Microbiology, vol. 28, no. 5, pp. 430-441, 2005.

[23] B. Ayna, S. Çelenk, F. Atakul, B. Sezgin, and T. Özekinci, "Evaluation of clinical and microbiological features of deep carious lesions in primary molars," Journal of Dentistry for Children, vol. 70, no. 1, pp. 15-18, 2003.

[24] L. Bjørndal and T. Larsen, "Change in the cultivable flora in deep carious lesion following a stepwise excavation procedure," Caries Research, vol. 34, no. 6, pp. 502-508, 2000.

[25] M.-S. Kang, J.-S. Oh, H.-C. Lee et al., "Inhibitory effect of Lactobacillus reuteri on periodontopathic and cariogenic bacteria," Journal of Microbiology, vol. 49, no. 2, pp. 193-199, 2011.

[26] K. Hatakka, A. J. Ahola, H. Yli-Knuuttila et al., "Probiotics reduce the prevalence of oral Candida in the elderly-a randomized controlled trial," Journal of Dental Research, vol. 86, no. 2, pp. 125-130, 2007. 
[27] M. Matsumoto, M. Tsuji, H. Sasaki et al., "Cariogenicity of the probiotic bacterium Lactobacillus salivarius in rats," Caries Research, vol. 39, no. 6, pp. 479-483, 2005.

[28] R. Byun, M. A. Nadkarni, K.-L. Chhour, F. E. Martin, N. A. Jacques, and N. Hunter, "Quantitative analysis of diverse Lactobacillus species present in advanced dental caries," Journal of Clinical Microbiology, vol. 42, no. 7, pp. 3128-3136, 2004.

[29] S. I. Smith, A. J. Aweh, A. O. Coker, K. O. Savage, D. A. Abosede, and K. S. Oyedeji, "Lactobacilli in human dental caries and saliva," Microbios, vol. 105, no. 411, pp. 77-85, 2001.

[30] S. Nagaoka, H.-J. Liu, K. Minemoto, and M. Kawagoe, "Microbial induction of dentinal caries in human teeth in vitro," Journal of Endodontics, vol. 21, no. 11, pp. 546-551, 1995. 

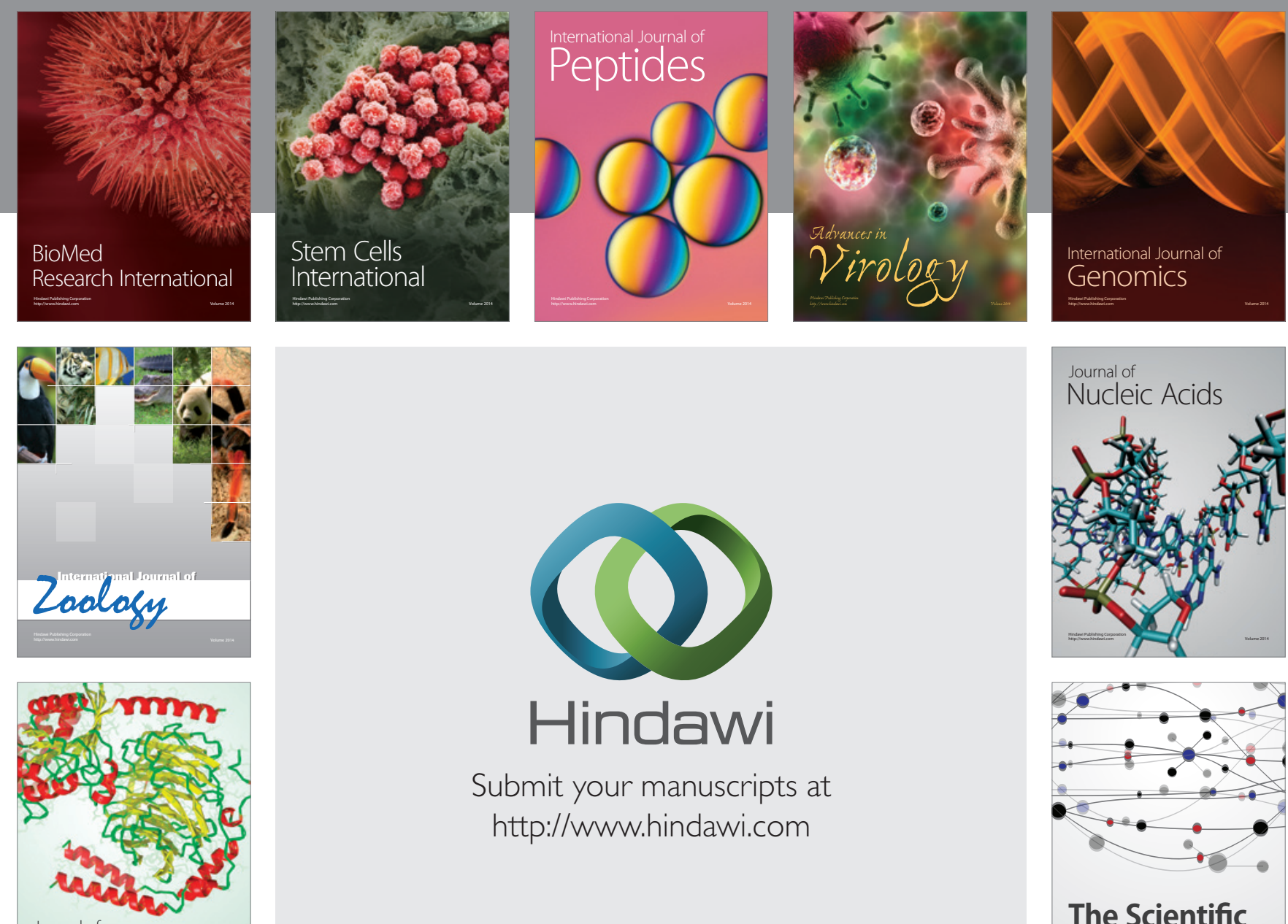

Submit your manuscripts at

http://www.hindawi.com

Journal of
Signal Transduction
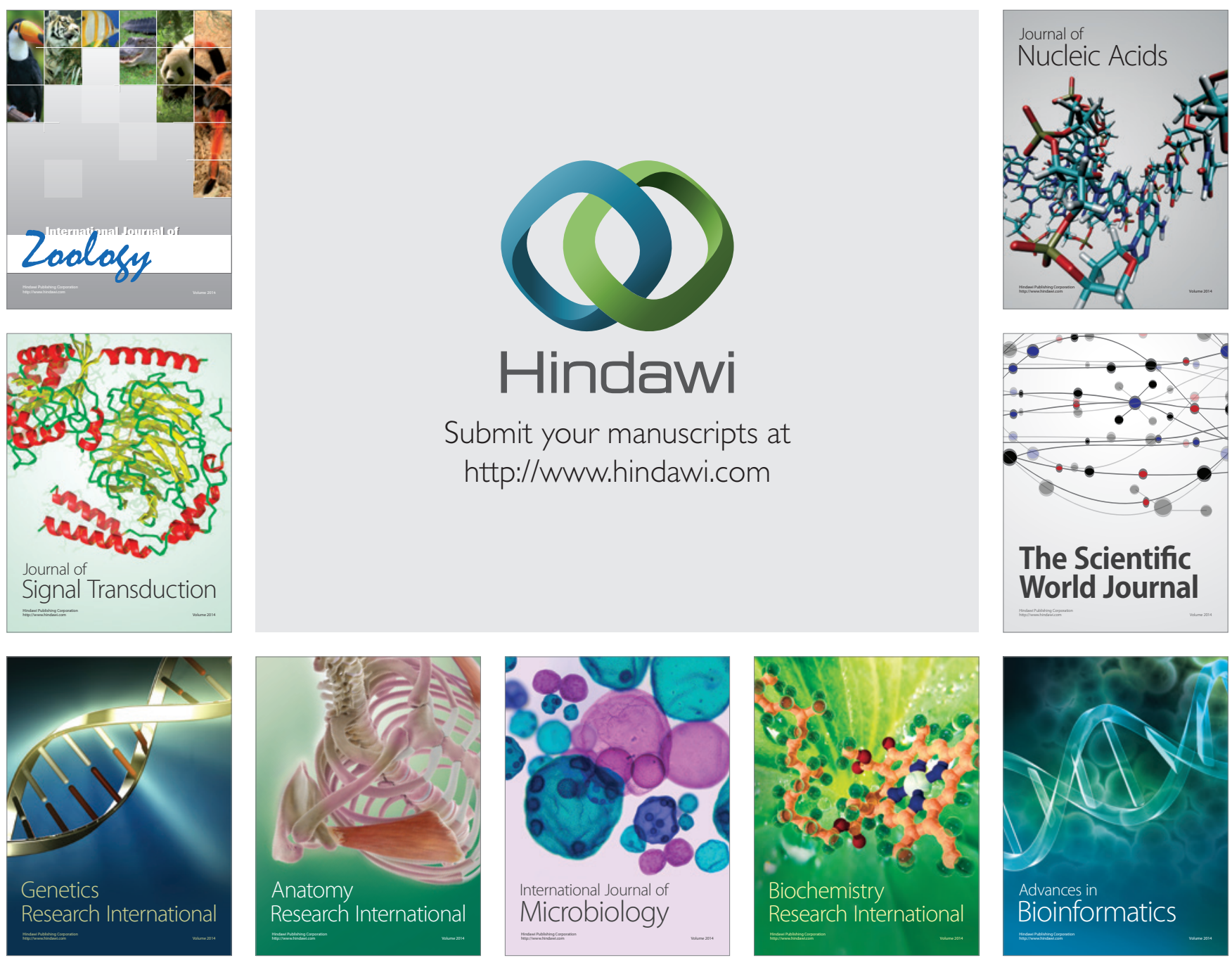

The Scientific World Journal
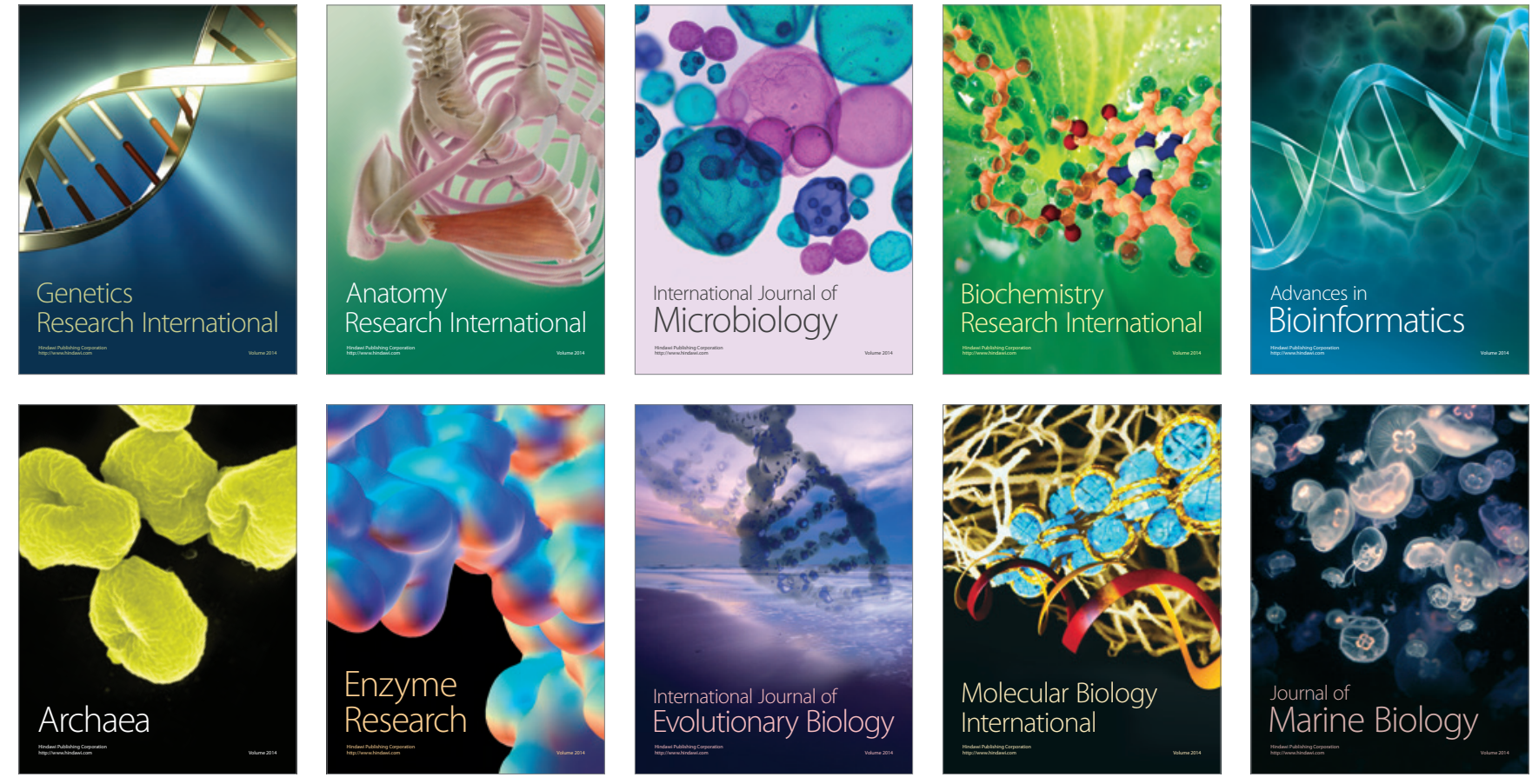